\title{
Drug resistance originating from a TGF- $\beta$ /FGF-2-driven epithelial-to-mesenchymal transition and its reversion in human lung adenocarcinoma cell lines harboring an EGFR mutation
}

\author{
RYOTA KURIMOTO ${ }^{1}$, SHUNICHIRO IWASAWA ${ }^{1}$, TAKAHIRO EBATA ${ }^{1}$, TSUKASA ISHIWATA ${ }^{2}$, IKUO SEKINE ${ }^{4}$, \\ YUJI TADA $^{2}$, KOICHIRO TATSUMI $^{2}$, SHUHEI KOIDE $^{3}$, ATSUSHI IWAMA ${ }^{3}$ and YUICHI TAKIGUCHI ${ }^{1}$ \\ Departments of ${ }^{1}$ Medical Oncology, ${ }^{2}$ Respirology and ${ }^{3}$ Cellular and Molecular Medicine, Graduate School of Medicine, \\ Chiba University, Inohana, Chuo-ku, Chiba 260-8670; ${ }^{4}$ Department of Medical Oncology, \\ Faculty of Medicine, University of Tsukuba, Tennodai, Tsukuba 305-8575, Japan
}

Received January 14, 2016; Accepted February 20, 2016

DOI: 10.3892/ijo.2016.3419

\begin{abstract}
Epithelial-to-mesenchymal transition (EMT) is a malignant cancer phenotype characterized by augmented invasion and metastasis, chemoresistance, and escape from host-immunity. This study sought to identify efficient methods for inducing EMT reversion, to evaluate alterations in chemosensitivity and immune-protectiveness, and to elucidate the underlying mechanisms. In this study, the human lung adenocarcinoma cell lines PC-9 and HCC-827, harboring an EGFR mutation, were treated with TGF- $\beta$ and FGF-2 to induce EMT. The phenotypic alterations were evaluated by RT-PCR, fluorescent immunohistochemistry, cell-mobility, and flow cytometry. Chemosensitivity to gefitinib and cisplatin was evaluated using an MTT assay and apoptosis. Immune-protectiveness was evaluated by PD-L1 expression. A combination of TGF- $\beta$ and FGF-2 efficiently induced EMT in both cell lines: through Smad3 pathway in PC-9, and through Smad3, MEK/Erk, and mTOR pathways in HCC-827. The mTOR inhibitor PP242, metformin, and DMSO reverted EMT to different extent and through different pathways, depending on the cell lines. EMT induction reduced the sensitivity to gefitinib in both cell lines and to cisplatin in HCC-827, and it increased PD-L1 expression in both cell lines. EMT reversion using each of the 3 agents partly restored chemosensitivity and suppressed PD-L1 expression. Thus, chemoresistance and increased PD-L1 expression caused by EMT can be successfully reverted by EMT-reverting agents.
\end{abstract}

Correspondence to: Professor Yuichi Takiguchi, Department of Medical Oncology, Graduate School of Medicine, Chiba University, Inohana, 1-8-1 Inohana, Chuo-ku, Chiba 260-8670, Japan E-mail: takiguchi@faculty.chiba-u.jp

Key words: epithelial-mesenchymal transition, chemoresistance, epidermal growth factor receptor mutation, PD-L1, non-small cell lung cancer

\section{Introduction}

The epithelial-to-mesenchymal transition (EMT) enables cancer to invade and metastasize $(1,2)$. In addition, accumulating evidence strongly suggests that the EMT induces cancer chemoresistance (3) and radioresistance $(4,5)$ and has an immunoprotective effect (6). Therefore, the EMT constitutes a major malignant propensity to cancer development and is a major obstacle to curing cancer. TGF- $\beta$ is a well-known driving factor of the EMT in many cancers (7). Activations of the Smad3, PI3K/Akt/mTOR, and MEK/Erk cascades are thought to be key mechanisms by which TGF- $\beta$ induces EMT (8-11). FGF-2 also induces EMT through the activation of the MEK/Erk signaling pathway. Moreover, a combination of TGF- $\beta$ and FGF-2 strongly induces EMT because TGF- $\beta$ induces isoform switching of the FGF-receptor and increases cellular sensitivity to FGF-2 (12). All these signaling pathways ultimately upregulate the transcriptional factors slug, snail, and ZEB1, to induce EMT (13-15).

Recent advances in cancer biology have expanded therapeutic modalities to include cytotoxic chemotherapy, targeted therapy, and immune-checkpoint therapy. For example, the survival time of patients with advanced non-small cell lung cancer (NSCLC) harboring a mutation in either the epidermal growth factor receptor $(E G F R)$ gene or the anaplastic lymphoma kinase $(A L K)$ gene has been greatly prolonged using tyrosine kinase inhibitors (16) for the corresponding mutation. Nevertheless, cancer still recurs even after the drastic effects of targeted therapy. Although the mechanisms underlying drug resistance, either to cytotoxic or targeted agents, are not fully understood, they consist of mutational and non-mutational mechanisms. EMT is one of the non-mutational mechanisms of drug resistance (3). For example, EMT markers were reportedly upregulated in patients with NSCLC showing resistance to cisplatin-based chemoradiotherapy (17). EMT is also reportedly related to resistance to docetaxel in patients with prostate cancer (18). The results of several in vitro experiments have supported these clinical observations: EMT markers were upregulated in ovarian cancer cell lines resistant to paclitaxel (19), morphological changes suggesting EMT were observed 
in colon cancer cells resistant to oxaliplatin (20), and the knockdown of snail increased the sensitivity of NSCLC cells to cisplatin (21). Therefore, the EMT appears to be closely related to resistance to cytotoxic agents. In addition, EMT is a candidate for the application of a non-mutational resistance mechanism to targeted therapy. The in vitro induction of EMT rendered human NSCLC cells harboring EGFR mutations less sensitive to EGFR-TKIs (22-24).

Therefore, EMT reversion to the original epithelial phenotype might be a new therapeutic strategy for overcoming resistance to chemotherapy and/or targeted therapy. Although some agents, including metformin and mTOR inhibitors, can reportedly revert the EMT phenotype, the relationship between this phenomenon and changes in drug sensitivity is not fully understood. This study examined the molecular mechanisms underlying EMT induction and reversion by investigating changes in drug sensitivity and immuneprotectiveness according to EMT induction and reversion in human lung adenocarcinoma cell lines harboring an EGFR mutation.

\section{Materials and methods}

Cells and reagents. Human lung adenocarcinoma cell lines, PC-9 and HCC-827, were used throughout the study. PC-9 was purchased from Riken Cell Bank (accession no. RCB4455; Tsukuba, Japan). HCC-827 was obtained from the American Type Culture Collection (accession no. CRL-2868; Manassas, VA, USA). The cell lines have an identical activating mutation in EGFR: a deletion (del E746-A750) in exon 19. The cells were cultured as a monolayer in RPMI-1640 medium (cat. no. R8758; Sigma-Aldrich, St. Louis, MO, USA) supplemented with $10 \%$ fetal bovine serum (FBS), $100 \mathrm{U} / \mathrm{ml}$ penicillin and $100 \mathrm{mg} / \mathrm{ml}$ streptomycin (cat. no. 10378-016; Life Technologies, Carlsbad, CA, USA) in a $37^{\circ} \mathrm{C}$ humidified atmosphere containing $5 \% \mathrm{CO}_{2}$.

The EGFR-TKI gefitinib (cat. no. 3000; Tocris Bioscience, Ellisville, MO, USA) was dissolved in DMSO (cat. no. D2650; Sigma-Aldrich) and stored at $-20^{\circ} \mathrm{C}$ until use. Cisplatin at a concentration of $0.5 \mathrm{mg} / \mathrm{ml}(\mathrm{pH} 2.5-5.5)$ was purchased from Nihon Kayaku (Tokyo, Japan) and stored at $4^{\circ} \mathrm{C}$. Metformin (1,1-dimethylbiguanide hydrochloride, cat. no. D150959-5G; Sigma-Aldrich) was dissolved in phosphate-buffered saline (PBS) at a concentration of $100 \mathrm{mM}$ and stored at $4^{\circ} \mathrm{C}$. PP242 (cat. no. 165-24441; Wako, Osaka, Japan), a potent inhibitor of mTOR complex 1 and $\mathrm{C} 2$ (mTOR-C1 and -C2), was dissolved in DMSO at concentrations of $10 \mathrm{mM}$ and stored in aliquots at $-80^{\circ} \mathrm{C}$. Each agent was diluted in complete medium, and the final concentration of DMSO was $<0.001 \%$. Recombinant human TGF- $\beta 1$ was purchased from PeproTech (cat. no. 100-21C; Rock Hill, NJ, USA), and recombinant human FGF-2 was purchased from Cell Signaling Technology (cat. no. 8910LC; Beverly, MA, USA).

Mouse monoclonal anti- $\beta$-actin (cat. no. A2228) and anti-fibronectin (cat. no. F3648) were purchased from SigmaAldrich. Rabbit monoclonal anti-vimentin (cat. no. 5741P), anti-slug (cat. no. 9585S), anti-p70S6K (cat. no. 2708S), antiphospho-p70S6K (cat. no. 9205S), anti-Erk1/2 (cat. no. 9102S), anti-phospho-Erk1/2 (cat. no. 9101S), anti-Akt (cat. no. 9272S), anti-phospho-Akt on Ser473 (cat. no. 9271S), anti-Smad3 (cat. no. 9523S) and anti-phospho-Smad3 antibodies (cat. no. 9516S) were purchased from Cell Signaling Technology. The anti-E cadherin antibody was purchased from BD Transduction Laboratory (cat. no. 610181; Lexington, KY, USA). AntiPD-L1/CD274 monoclonal antibody was purchased from Spring Bioscience (cat. no. M4420; Pleasanton, CA, USA). Anti-rabbit IgG-horseradish peroxidase-linked antibody was purchased from Medical and Biological Laboratories (cat. no. 458; Nagoya, Japan). ECL ${ }^{\mathrm{TM}}$ horseradish peroxidase linked anti-mouse antibody was purchased from GE Healthcare (cat. no. NA931; Uppsala, Sweden). Anti-mouse IgG Fab2 Alexa Fluor ${ }^{\circledR} 488$ molecular probe (cat. no. 4408S) and anti-rabbit IgG Fab2 Alexa Fluor ${ }^{\circledR} 555$ molecular probe (cat. no. 4413S) was purchased from Cell Signaling Technology.

In vitro induction and reversion of EMT. EMT was induced by treating cells with TGF- $\beta$ and/or FGF-2. Based on a series of preliminary experiments, a combination of TGF- $\beta$ at a concentration of $10 \mathrm{ng} / \mathrm{ml}$ and FGF-2 at a concentration of $10 \mathrm{ng} / \mathrm{ml}$ was admixed into the complete medium for inducing EMT after $24 \mathrm{~h}$ of serum starvation. To evaluate the EMT phenotypes, cells harvested at $48 \mathrm{~h}$ after the admixture of the agents were used. For EMT reversion, PP242 at a concentration of $1.0,10$ or $100 \mathrm{nM}$, metformin at a concentration of $0.1,1.0$ or $10 \mathrm{mM}$, or DMSO at a concentration of 0.1 or $1.0 \%$ ( $\mathrm{vol} / \mathrm{vol})$ was added to cells in which the EMT had already been induced, with TGF- $\beta /$ FGF- 2 being supplemented continuously. The phenotypes were evaluated after $72 \mathrm{~h}$ of culture with the reverting agent.

Evaluation of cell viability. Cell viability was determined using the MTT dye reduction method. A total of 500 cells/well were plated in 96-well culture plates. After $24 \mathrm{~h}$ of serum-free culture, the cells were treated to induce EMT and to revert EMT, as previously described. Then, the cells were treated with various concentrations of gefitinib or cisplatin for an additional $72 \mathrm{~h}$ of culture. To each well, $15 \mu \mathrm{l}$ of dye solution (cat. no. G402A; Promega, Madison, WI, USA) was added for further incubation at $37^{\circ} \mathrm{C}$ for $4 \mathrm{~h}$, followed by the addition of $100 \mu 1$ of stop solution (cat. no. G4001; Promega) for a further $1 \mathrm{~h}$ of incubation. The absorbance at $570 \mathrm{~nm}$ in the resulting solution was measured using Infinite ${ }^{\circledR} 200$ PRO (FPRO-T; Tecan, Seestrasse, Switzerland). Cell viability was determined by dividing the absorbance value of the treated cells by that of the untreated cells.

Real-time PCR (RT-PCR). The expression of mRNA was semi-quantified using RT-PCR with the TaqMan ${ }^{\circledR}$ Gene Expression Assays, Step One Plus Real-Time PCR system, and Step One Software (Life Technologies). After culturing cells at $80 \%$ confluence in 6 -well culture plates, the total RNA was extracted using the RNeasy ${ }^{\circledR}$ Mini kit (cat. no. 74104; Qiagen, Venlo, Limburg, The Netherlands) and the cDNA was immediately synthesized using SuperScript ${ }^{\circledR}$ First-Strand Synthesis for RT-PCR (cat. no. 11904-018; Life Technologies) for RT-PCR according to the manufacturer's instructions. The gene expression data were calculated relative to the glyceraldehyde-3-phosphate dehydrogenase (GAPDH) level. TaqMan probes for GAPDH, E-cadherin, vimentin, 
fibronectin, slug, and PD-L1 were obtained by ordering from Applied Biosystems through Life Technologies (assay identification numbers: Hs02758991_g1, Hs01023894_m1, Hs00185584_m1, Hs00365052_m1, Hs00950344_m1 and Hs01125301_m1).

Western blot analysis. Cells prepared in a manner similar to that used for the mRNA isolation studies mentioned above were lysed in RIPA buffer (cat. no. 89900; Thermo Fisher Scientific) with protease and phosphatase inhibitor (cat. no. 1861281; Thermo Fisher Scientific) on ice to extract the total protein. After measurement with a BCA assay (Pierce ${ }^{\circledR}$ BCA Protein assay kit, cat. no. 23225; Thermo Fisher Scientific, Rockford, IL, USA), $10 \mu \mathrm{g}$ of protein in each lane in a $10 \%$ precast gel (Mini-PROTEAN ${ }^{\circledR}$ TGX $^{\mathrm{TM}}$, cat. no. 456-1025, Bio-Rad, Hercules, CA, USA) was electrophoresed using the Powger Pac Basic, Mini PROTEAN ${ }^{\circledR}$ Tetra System (Bio-Rad), followed by transfer to polyvinylidenedifluoride membranes (TransBlot $^{\circledR}$ Turbo $^{\mathrm{TM}}$ Transfer Pack 0.2 $\mu \mathrm{m}$ PVDF, cat. no. 170-4156; Bio-Rad) using the Trans-Blot Turbo ${ }^{\text {TM }}$ Transfer System (Bio-Rad). The membranes were probed with antibodies using the iBind ${ }^{\mathrm{TM}}$ Western Device, Cards and Solution kit (cat. no. SLF 1000, 1010 and 1020; Novex by Life Technologies), followed by visualization using an enhanced chemiluminescence substrate kit (Clarify $^{\mathrm{TM}}$ Western ECL Substrate, cat. no. 170-5060; Bio-Rad). The images were analyzed using Molecular imager ${ }^{\circledR}$ ChemiDOC $^{\text {TM }}$ XRS+ (Bio-Rad) and quantified by Image Lab ${ }^{\circledR}$ Software (Bio-Rad). The expression of phosphorylated proteins was also determined as the relative ratio per total protein.

Fluorescent immunohistochemistry. For the fluorescent immunohistochemical evaluation of protein expression, cells were cultured up to $80 \%$ confluence in a 4 -well chamber slide (cat. no. 177399; Thermo Fisher Scientific) and then washed with PBS and fixed with $4 \%$ paraformaldehyde at room temperature for $15 \mathrm{~min}$, followed by incubation with the primary antibodies (diluted in PBS with $1 \%$ bovine serum albumin) at $4^{\circ} \mathrm{C}$ overnight. Non-specific binding was blocked using $2 \%$ bovine serum albumin. Then, the cells were washed with PBS and incubated with secondary antibodies at room temperature for $30 \mathrm{~min}$ before being mounted in ProLong ${ }^{\circledR}$ Gold Antifade Reagent with 4', 6-diamidino-2-phenylindole (DAPI) (cat. no. 8961, Cell Signaling Technology) for observation with EVOS FL (AMF4300; Life Technologies).

Apoptosis assay. Apoptosis was examined using flow cytometry with Annexin V-fluorescein isothiocyanate (FITC) and propidium iodide (PI) (cat. no. 556547; BD Biosciences, San Jose, CA, USA). Briefly, cells were treated with various concentrations of gefitinib or cisplatin for $24 \mathrm{~h}$, trypsinized, washed with cold PBS, and suspended in binding buffer (BD Biosciences) at a concentration of $1 \times 10^{7}$ cells $/ \mathrm{ml}$. Thereafter, they were stained with $5 \mu \mathrm{l}$ of Annexin V-FITC and $5 \mu \mathrm{l}$ of PI in $100 \mu \mathrm{l}$ of cell suspension and incubated for 15 min at room temperature in the dark for processing using flow cytometry. All the early apoptotic cells (Annexin V-positive, PI-negative), necrotic/late apoptotic cells (double positive), and living cells (double negative) were counted using FACSCanto II $^{\mathrm{TM}}$ (BD Biosciences).
Cell cycle. The cell cycle distributions were determined using a PI single-color flow cytometry (FACSCanto II), according to the manufacturer's instructions. Briefly, cells were trypsinized and washed twice with cold PBS, then fixed with $70 \%$ ethanol. Before analysis, the cell suspensions were washed with PBS, suspended in $100 \mu \mathrm{l}$ of binding buffer containing $5 \mu \mathrm{l}$ of PI at a concentration of $1 \times 10^{7}$ cells $/ \mathrm{ml}$, followed by incubation for $15 \mathrm{~min}$ at room temperature in the dark.

Wound healing assay. The cell migration ability was evaluated using a wound healing assay. Cells were cultured until they became confluent in 6-well plates, at which time the surfaces of the plates were scratched with micropipette tips (cat. no. 2069-05; Thermo Fisher Scientific) and the culture medium was immediately exchanged, followed by culture for a further $9 \mathrm{~h}$. The scratched wounds were viewed using an inverted microscope (x10 objective) (ECLIPSE TS100; Nikon, Tokyo, Japan). The scratched areas were quantified using Image $\mathbf{J}$ (from National Institutes of Health), and the wound closure rates were determined as a percentage of the total repaired area per hour and were normalized to the control.

Statistical analyses and ethical considerations. Data are presented as the means \pm standard errors, and differences between groups were evaluated using the Student's t-test. A P-value of $<0.05$ (2-tailed) was considered statistically significant. All the experiments were conducted in close adherence to the institutional regulations.

\section{Results}

In vitro induction of EMT. The EMT phenotype was confirmed by a decreased expression of E-cadherin (an epithelial marker) and an increased expression of vimentin, fibronectin (mesenchymal markers), and slug. RT-PCR for the HCC-827 cells revealed that TGF- $\beta$ upregulated vimentin, fibronectin, and slug without downregulating E-cadherin; that FGF-2 downregulated E-cadherin without upregulating vimentin, fibronectin, and slug; and that the combination of TGF- $\beta$ and FGF-2 downregulated E-cadherin and upregulated vimentin, fibronectin, and slug, resulting in a perfect EMT phenotype. In the PC-9 cells, in contrast, the combination of TGF- $\beta$ and FGF-2 upregulated vimentin, fibronectin, and slug without downregulating E-cadherin (Fig. 1A). The altered expressions of E-cadherin at the cell junctions and of fibronectin in the cytoplasm were further confirmed using fluorescent immunohistochemistry, except that the PC-9 cells failed to show any change in E-cadherin expression (Fig. 1B). The morphological changes in the cells were concordant with these observations: that is, the HCC-827 cells became elongated in morphology and less adhesive when they exhibited the EMT phenotype, whereas the PC-9 cells were unaltered in morphology, since the original cells were already ostensibly elongated and less adhesive (Fig. 2A). A wound healing assay disclosed increased cell-mobility for the EMT phenotype in both cell lines (Fig. 2B). The accumulation of G0/G1 cells in the EMT phenotype was observed in a cell cycle analysis (Fig. 2C). These findings clearly indicate the successful induction of EMT in both cell lines. Based on this fact, the combination of TGF- $\beta$ and FGF-2 was used to induce EMT in the remainder of this study. 
A

HCC-827

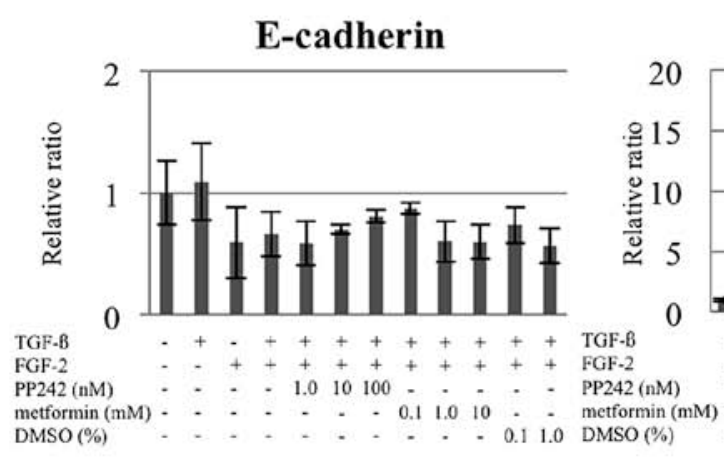

mesenchymal marker

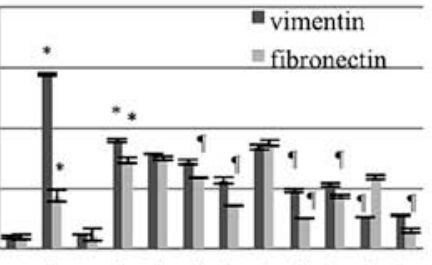

- ++++++++++ TGF

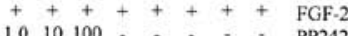

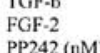

242 (nM) - - $1010100++++$ DMSO (\%)

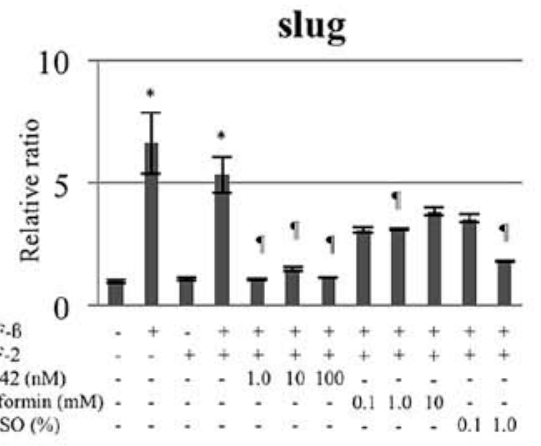

slug
E-cadherin

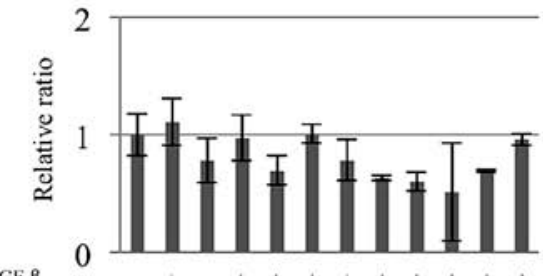

TGF- $B$

FGF-2

PP242 (nM)

metformin $(\mathrm{mM})$

DMSO $(\%)$

PC-9

B

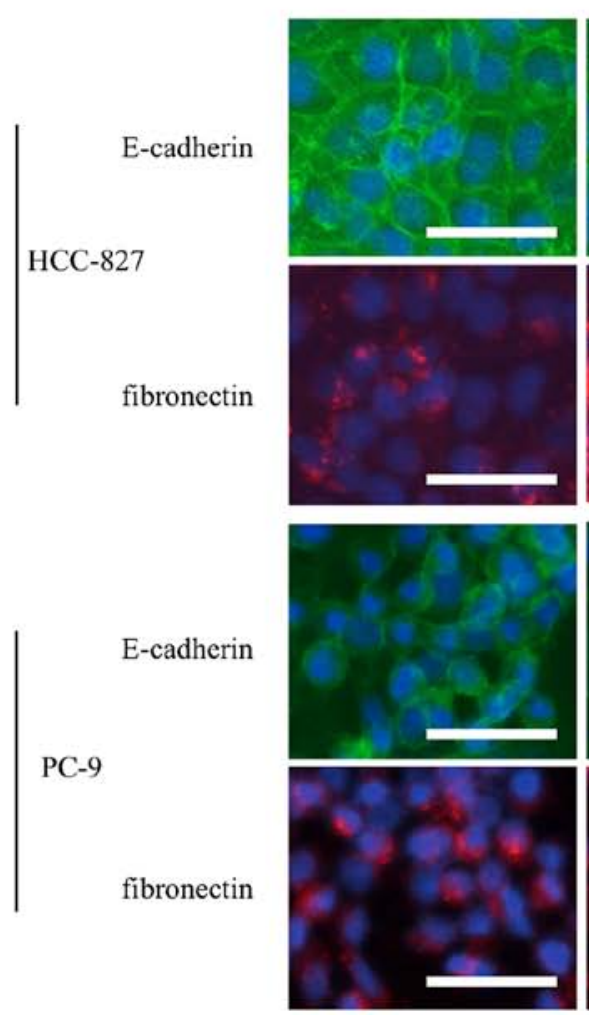

mesenchymal marker

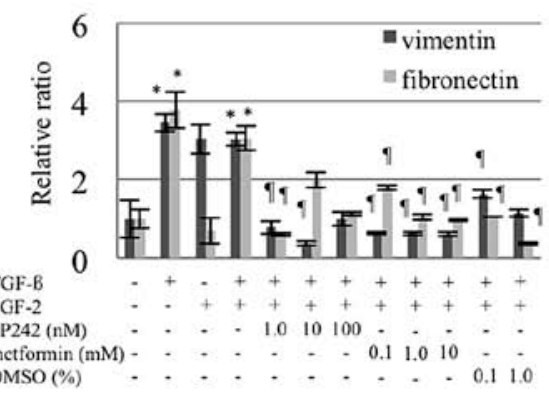

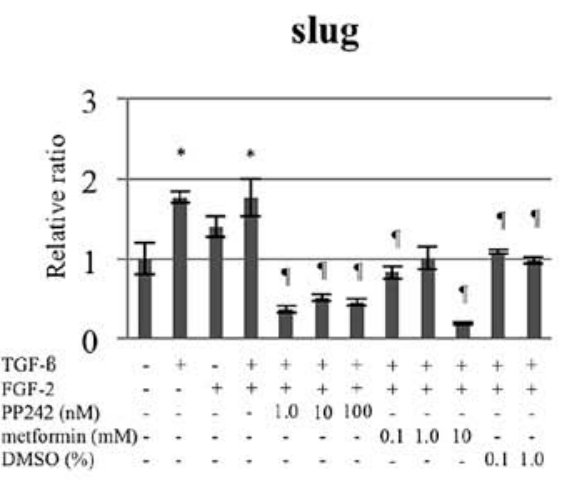

$\mathrm{TGF} \beta+\mathrm{FGF} 2$

TGF $\beta+F G F 2$
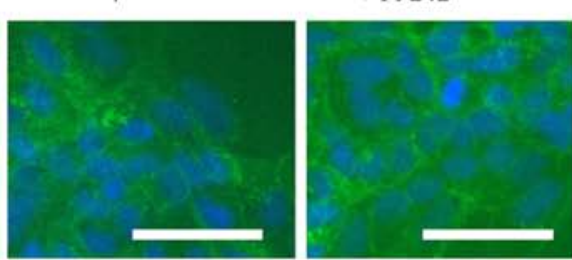

TGF $\beta+F G F 2$

+ metformin

TGF $\beta+$ FGF2
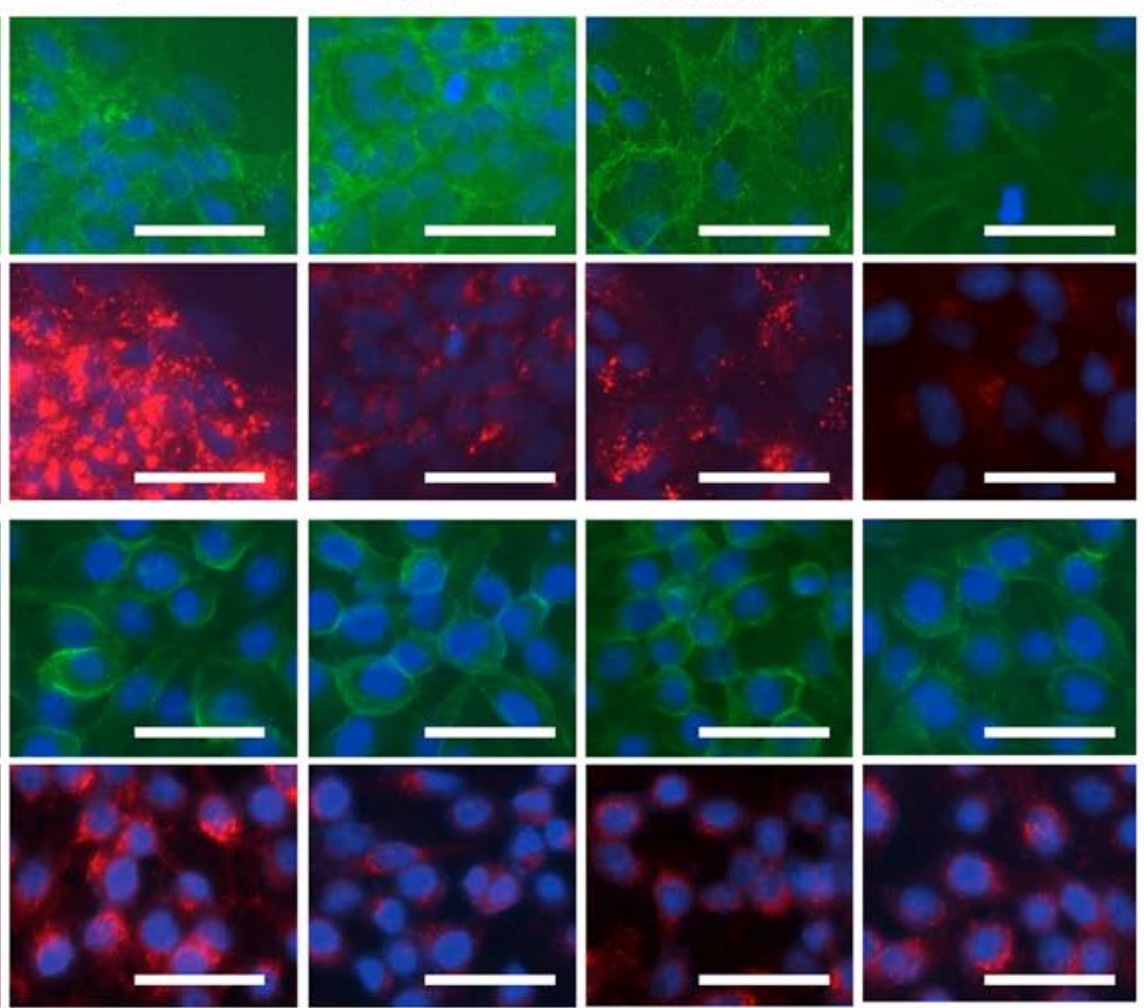

Figure 1. Evidence of EMT induction and reversion as assessed by changes in the expressions of E-cadherin, vimentin, fibronectin, and slug in the human adenocarcinoma lung cancer cell lines, HCC827 and PC9. (A) The relative ratio of mRNA normalized to that in the control was evaluated using RT-PCR for cells treated with/without TGF- $\beta$ (10 ng/ml) and/or FGF-2 (10 ng/ml). The treatment duration was $48 \mathrm{~h}$ after a $24-\mathrm{h}$ serum starvation period. TGF- $\beta$ alone and the combination of TGF- $\beta$ /FGF- 2 showed comparable effects on increasing the expression of the mesenchymal markers and slug in both cell lines, whereas the combination, but not TGF- $\beta$ alone, was effective in decreasing E-cadherin expression in HCC827. The combination was thereafter used to induce EMT throughout the study. In addition, PP242 (1.0, 10 or $100 \mathrm{nM})$, metformin $(0.1,1.0$ or $10 \mathrm{mM})$, and DMSO $(0.1$ or $1.0 \%)$ reverted the altered expression of these markers. Of note, treatment with these 3 drugs was started in cells that were already exhibiting EMT induction. The columns and bars represent the means and SEs ( $\mathrm{n}=6$, in triplicate) of the relative ratios compared with the controls, respectively. Statistically significant differences $(\mathrm{P}<0.05)$ compared with the control (no TGF- $\beta$ /FGF-2) and TGF- $\beta$ /FGF-2-treated cells are indicated by ${ }^{*}$ and ${ }^{\Im}$, respectively. (B) The changes in E-cadherin expression on the cell surface and the changes in fibronectin expression in the cytoplasm were confirmed using fluorescent immunohistochemical staining. The doses for PP242, metformin, and DMSO were $100 \mathrm{nM}, 1.0 \mathrm{mM}$, and $1.0 \%$, respectively. Cells were counterstained with DAPI. The bars represent $50 \mu \mathrm{m}$. 
A

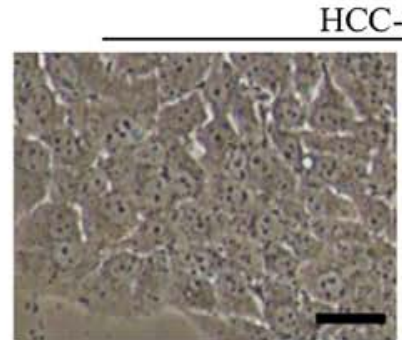

control
HCC -827

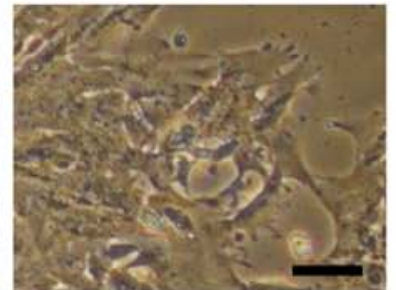

TGF-B + FGF-2

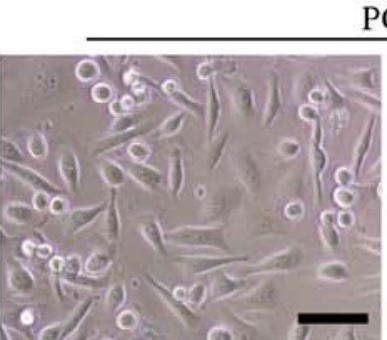

control
PC-9

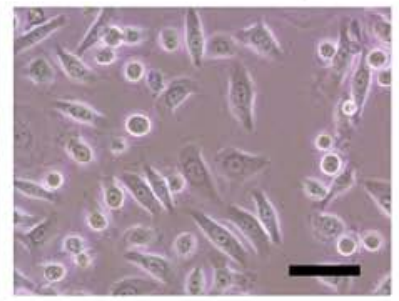

TGF-B + FGF-2

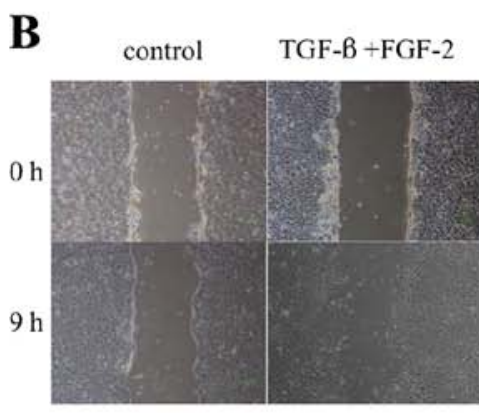

HCC-827 control

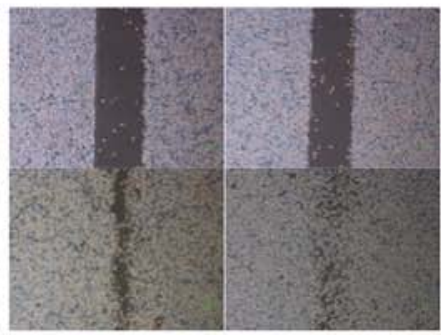

PC-9
HCC-827

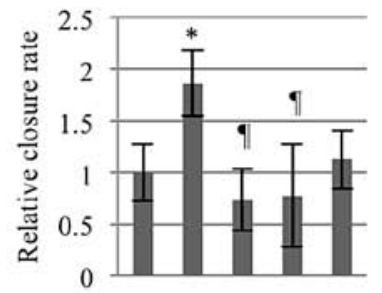

TGF- $\beta+F G F-2$ -

PP242

metformin

DMSO
PC-9

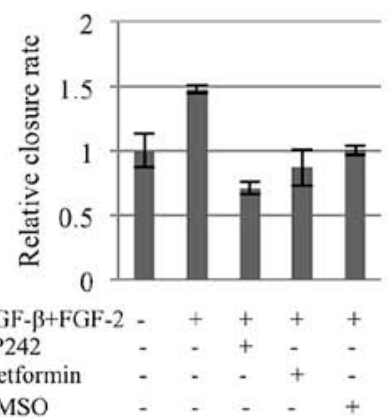

C

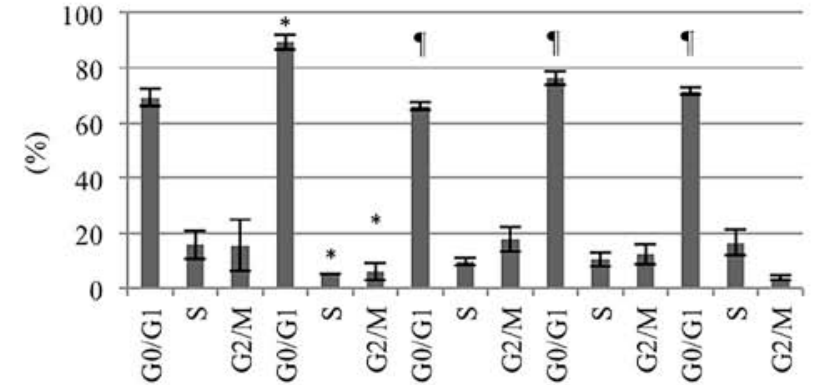

TGF- $\beta+F G F-2$

PP242

metformin

DMSO
HCC- 827

D

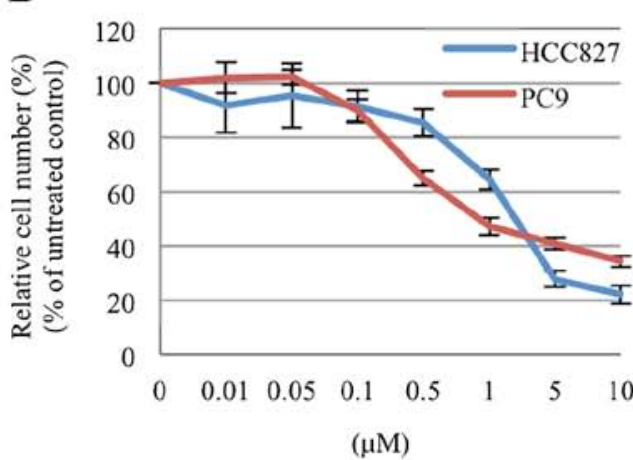

PP242

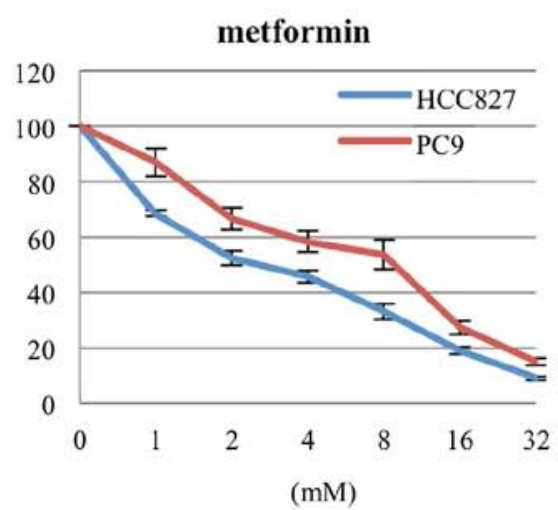

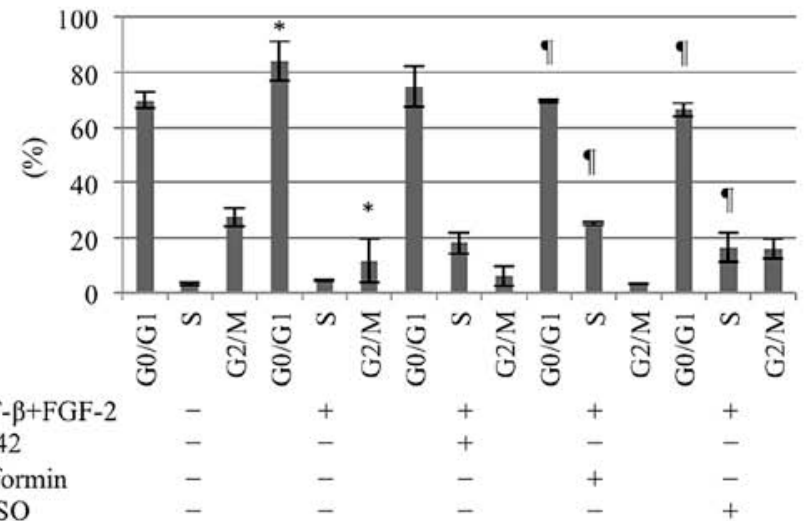

PC-9

\section{DMSO}

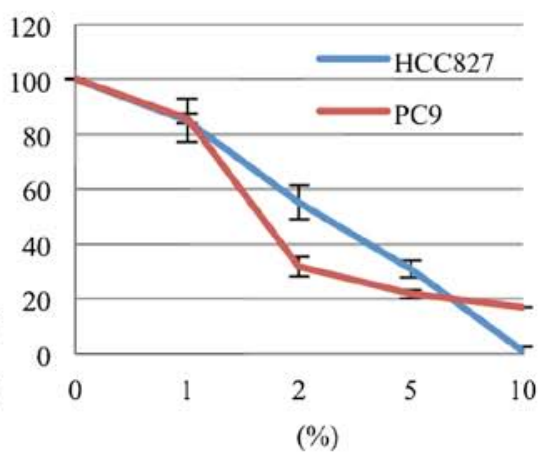

Figure 2. Phenotypic alterations according to EMT induction and reversion. (A) The combination of TGF- $\beta / F G F-2$ (10 ng/ml, each) induced clear morphological changes in HCC-827, resulting in an elongated and less-adhesive appearance; in contrast, the morphology of the PC-9 cells was unaltered, since the original cells already exhibited an elongated and less-adhesive appearance. The bars represent $50 \mu \mathrm{m}$. (B) A wound healing assay disclosed enhanced cell motility after treatment with TGF-3/FGF-2 in both cell lines, whereas PP242, metformin, and DMSO at the same doses as those used in Fig. 1B suppressed the phenomenon, as shown by the representative phase contrast images on the left. For quantification, the distance of cell migration was measured after $9 \mathrm{~h}$ in 3 fields $(\mathrm{n}=9$, in triplicate) for each group; the results are presented on the right. Statistically significant differences $(\mathrm{P}<0.05)$ compared with the control (no TGF- $\beta /$ FGF-2) and TGF- $\beta$ /FGF-2-treated cells are indicated by ${ }^{*}$ and " , respectively. (C) FACS analyses demonstrated a significant accumulation at the G0/G1 phases together with a significant decrease in the S and G2/M phases in TGF- $\beta /$ FGF-2-treated cells in both cell lines. PP242, metformin, and DMSO at the same doses as those used in Fig. 1B reverted these alterations. Statistically significant differences $(\mathrm{P}<0.05)$ compared with the control (no TGF- $\beta /$ FGF-2) and TGF- $\beta$ /FGF-2-treated cells are indicated by " and ", respectively. (D) MTT assays for PP242, metformin, and DMSO revealed dose-dependent growth inhibition of the cells. Based on the results, the dose ranges for these 3 agents were determined so that growth inhibition was not so significant within these dose ranges. The dots and bars represent the means and SEs ( $n=3$, in triplicate), respectively. 
$\mathbf{A}$

\begin{tabular}{lllllllllll}
\multicolumn{3}{c}{ HCC-827 } & & & \multicolumn{1}{c}{ PC-9 } \\
- & + & + & + & + & - & + & + & + & + \\
- & - & + & - & - & - & - & + & - & - \\
- & - & - & + & - & - & - & - & + & - \\
- & - & - & - & + & - & - & - & - & +
\end{tabular}

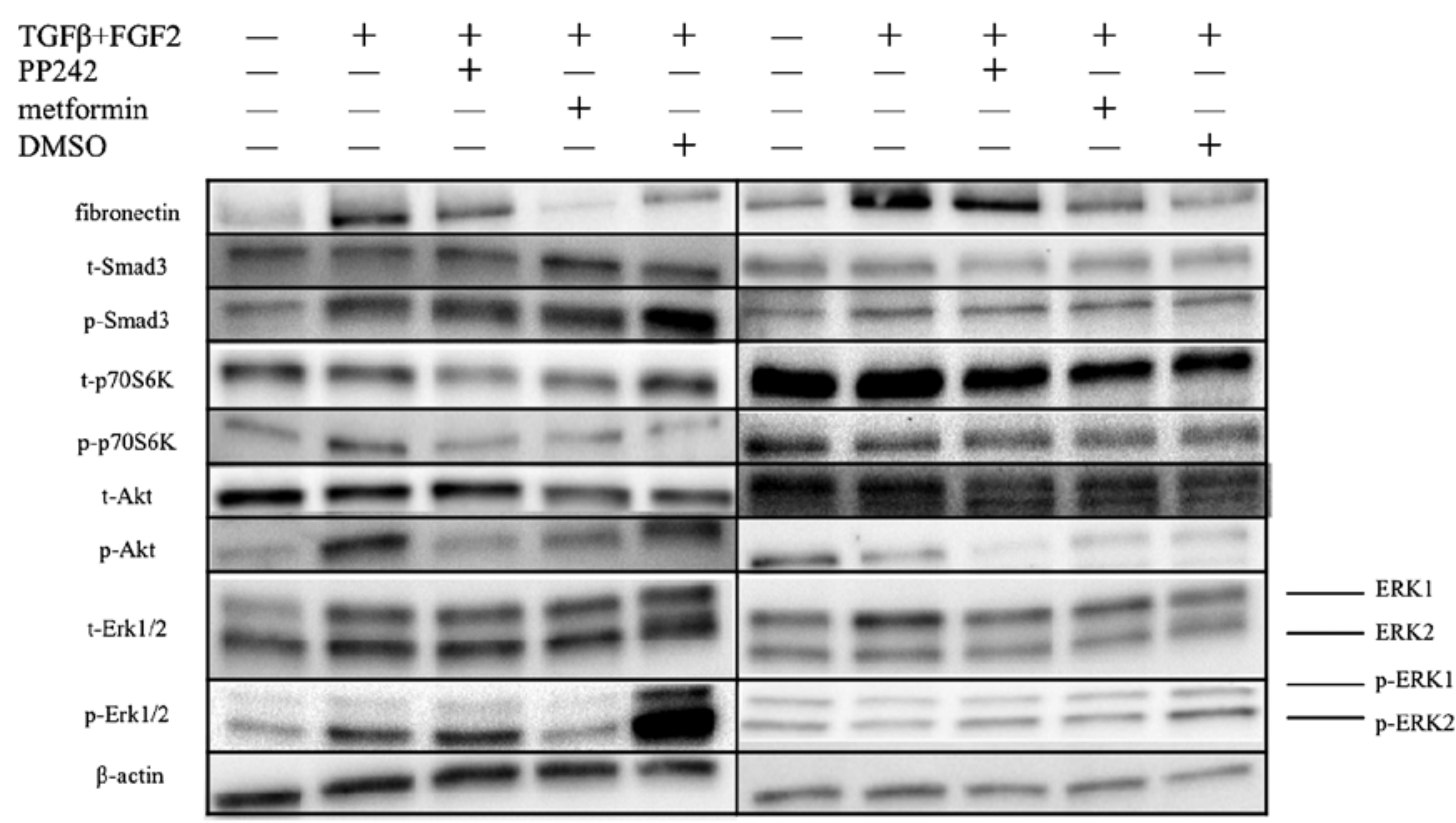

HCC-827

B

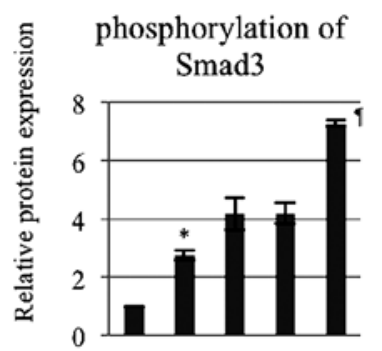

TGF- $\beta+$ FGF- 2

PP242

metformin

DMSO

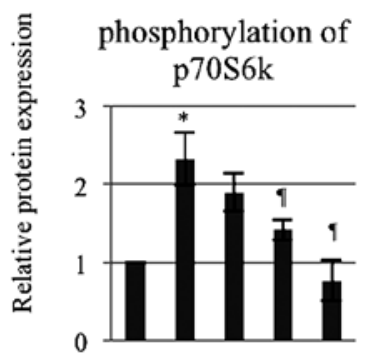

TGF- $\beta+F G F-2$

PP242

metformin

DMSO
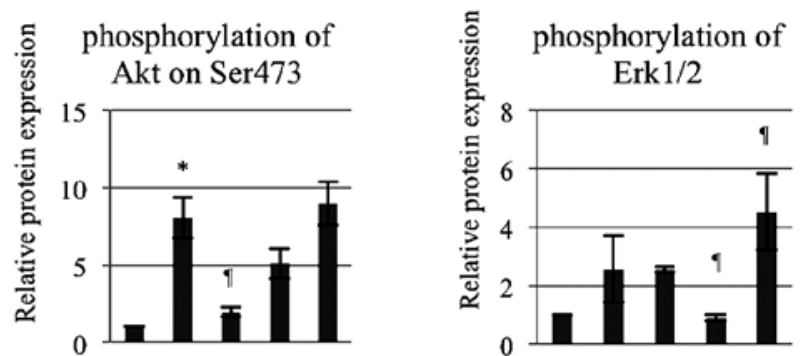

TGF- $\beta+$ FGF- 2
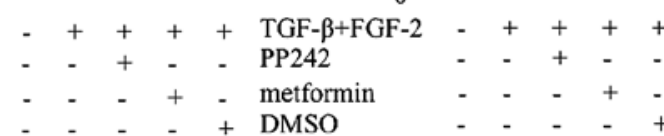

PP242

metformin

DMSO

PC-9

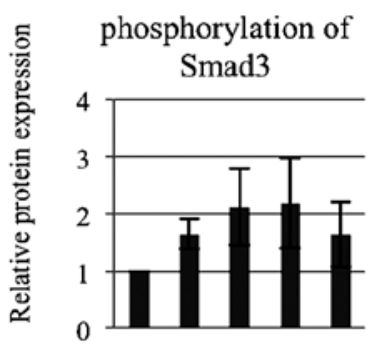

TGF- $\beta+F G F-2$ PP242

metformin

DMSO

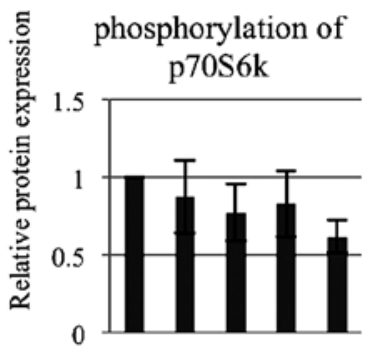

TGF- $\beta+$ FGF-2

PP242

metformin DMSO

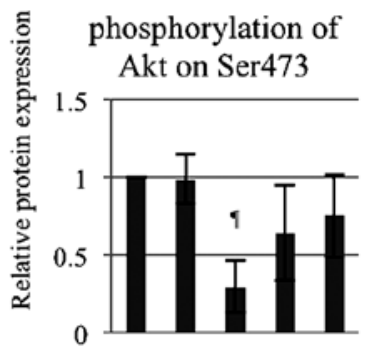

TGF- $\beta+F G F-2$

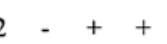

PP242

metformin

DMSO

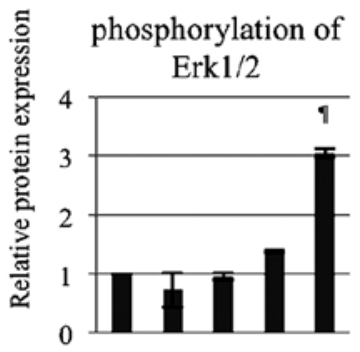

Figure 3. Phosphorylation of EMT-related pathway molecules in EMT induction and reversion. (A) Immunoblotting for phosphorylated Smad3, Erk1/2, p70S6K, and Akt (Ser473) and a $\beta$-actin control revealed the pathway-specific activation of these molecules. (B) Relative quantification of the blots shown in (A). As stated in detail in the text, EMT induction and reversion occurred via different pathways, depending on the cell lines and reverting agents. The columns and bars represent the means and SEs $(n=3$, in triplicate), respectively. Statistically significant differences $(\mathrm{P}<0.05)$ compared with the control $($ no TGF- $\beta /$ FGF-2) and TGF- $\beta$ /FGF-2-treated cells are indicated by * and "I, respectively.

Reversion of EMT induction. For the EMT reversion that was induced as described above, PP242, metformin, and DMSO were used. Because these agents are known to be cytotoxic, the cell survival curves resulting from the use of these agents 
were determined using an MTT assay (Fig. 2D). Based on the resulting data, doses of 1.0, 10, or $100 \mathrm{nM}$ for PP242; 0.1, 1.0, or $10 \mathrm{mM}$ for metformin; and 0.1 or $1.0 \%$ (vol/vol) for DMSO were chosen because their cytotoxicity was considered not to be very high at these doses. Although none of the agents significantly increased the expression of E-cadherin through EMT reversion in the PC-9 cells, PP242 and metformin administered at the lowest concentrations tended to increase E-cadherin expression in the HCC-827 cells. The three agents significantly decreased the expressions of vimentin, fibronectin, and slug in both cell lines (Fig. 1A). Fluorescent immunohistochemistry studies also supported the findings in HCC-827 cells: treatment with PP242, metformin, or DMSO suppressed the expression of fibronectin in the cytoplasm, with E-cadherin expression on the surface being unaltered (Fig. 1B). A wound healing assay disclosed the reversion of cell-migration activity with each of the agents in both cell lines (Fig. 2B). All three reverting agents suppressed the $\mathrm{G} 0 /$ G1 accumulation resulting from EMT induction and reverted the cell cycle to the pattern of the original cells in both cell lines (Fig. 2C). These observations indicate that the agents are capable of reverting the TGF- $\beta /$ FGF-2-induced EMT phenotype.

Alterations of Smad3, MEK/Erk, mTOR-C1/p70S6K, and mTOR-C2/Akt (Ser473) pathways according to EMT induction and reversion. The possible mechanisms underlying TGF- $\beta /$ FGF-2-induced EMT and its reversion by PP242, metformin, and DMSO were scrutinized by immunoblotting for phosphorylated Smad3, Erk1/2, p70S6K, and Akt (Ser473) (Fig. 3). In the PC-9 cells, the activation of the Smad3 pathway alone was related to EMT induction, whereas none of the 3 reverting agents suppressed the activated Smad3. All the agents showed a tendency to suppress the phosphorylation of Akt (Ser473). DMSO drastically and very paradoxically activated the phosphorylation of Erk1/2 (Fig. 3). On the contrary, in HCC-827, all the four pathways were related to the induction of EMT. As to the reverting agents, PP242 significantly suppressed the activated phosphorylation of Akt (Ser473) and showed a tendency to inhibit the activated phosphorylation of p70S6K; metformin significantly suppressed the activated phosphorylation of Erk1/2 and p70S6K and showed a tendency to inhibit the activated phosphorylation of Akt (Ser473); and DMSO significantly suppressed the activated phosphorylation of p70S6K, whereas it again significantly and paradoxically further activated the phosphorylation of Smad 3 and Erk1/2 (Fig. 3).

Alterations of drug sensitivity according to EMT induction and reversion. Both $\mathrm{PC}-9$ and $\mathrm{HCC}-827$ cells exhibiting TGF- $\beta / F G F-2$-induced EMT were significantly resistant to gefitinib, compared with untreated cells, whereas treatment with TGF- $\beta$ alone or FGF-2 alone had no effect or only a modest effect on sensitivity to gefitinib (Fig. 4A). On the contrary, PC-9 cells exhibiting TGF- $\beta / F G F-2$-induced EMT showed an unaltered sensitivity to cisplatin, whereas HCC-827

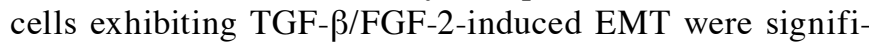
cantly resistant to cisplatin (Fig. 4A). PP242 and metformin had modest re-sensitizing effects for gefitinib in cells exhibiting EMT induction in both cell lines, with the effects of
DMSO being unequivocal. Although none of the agents had any effect on cisplatin sensitivity in the PC-9 cells, PP242 and DMSO had a modest re-sensitizing effect on cisplatin in the HCC-827 cells, whereas metformin seemingly had no effect on the sensitivity of the cells to cisplatin (Fig. 4A). These phenomena were precisely supported by the apoptosis assay. Apoptosis induced by gefitinib in the PC-9 and HCC-827 cells and apoptosis induced by cisplatin in the HCC-827 cells, but not in the PC-9 cells, was significantly suppressed in cells exhibiting the EMT phenotype, compared with the control cells (Fig. 4B). Nevertheless, PP242, metformin, and DMSO restored apoptosis with gefitinib, but not with cisplatin, in the PC-9 cells, whereas all three of the reverting agents restored apoptosis caused by either gefitinib or cisplatin that was suppressed in the HCC-827 cells exhibiting EMT induction (Fig. 4B).

Alteration of PD-L1 expression according to EMT induction and reversion. In the $\mathrm{HCC}-827$ cells, TGF- $\beta / \mathrm{FGF}-2$-induced EMT cells were related to a strong increase in PD-L1 expression, and metformin and DMSO, but not PP242, suppressed this phenomenon. The PC-9 cells also displayed a similar phenomenon, although the difference was not statistically significant (Fig. 5A). Fluorescent immunohistochemistry for PD-L1 expression on the cellular membranes supported these findings, except that PP242 significantly suppressed EMT-induced PD-L1 overexpression (Fig. 5B), in contrast to the absence of any effect when assessed using RT-PCR (Fig. 5A).

\section{Discussion}

This study, which was performed using two NSCLC cell lines harboring an EGFR mutation, confirmed the induction of the EMT using a combination of TGF- $\beta$ and FGF-2. It also demonstrated the reversion of EMT induction using any of the agents, PP242, metformin, or DMSO. These phenotypic changes were supported by morphological changes; the altered expression of an epithelial marker, mesenchymal markers, and slug; altered cell mobility; and an altered cell cycle, with the slight exception that the expression of E-cadherin was unaltered among the original phenotype, induced EMT phenotype, and reverted phenotype in PC-9 cells. This exception, however, is concordant with a previously reported finding that the morphology and expression of E-cadherin were not significantly altered in PC-9 cells exhibiting EMT (25). To elucidate the mechanisms underlying this phenomenon, the known important pathways for EMT, Smad3 $(2,7,9,10)$, MEK/Erk $(2,7,8,11)$, mTOR-C1/ p70S6K $(2,7,11)$ and mTOR-C2/Akt (Ser473), (2,7,26), were examined. The results showed that all the pathways in the HCC-827 cells and the Smad3 pathway in the PC-9 cells were correlated with EMT induction. Whereas, the mechanisms involved in reverting the EMT seemed slightly more complex. PP242 significantly inhibited mTOR-C2/Akt in both cell lines and tended to inhibit mTOR-C1/p70S6K in HCC-827 cells; metformin significantly inhibited MEK/Erk and mTOR-C1/ p70S6K in HCC-827 cells and tended to inhibit mTOR-C2/ Akt in both cell lines; and DMSO inhibited mTOR-C1/ p70S6K in both cell lines but had some paradoxical effects on the MEK/Erk pathway. This paradoxical effect of DMSO 
A
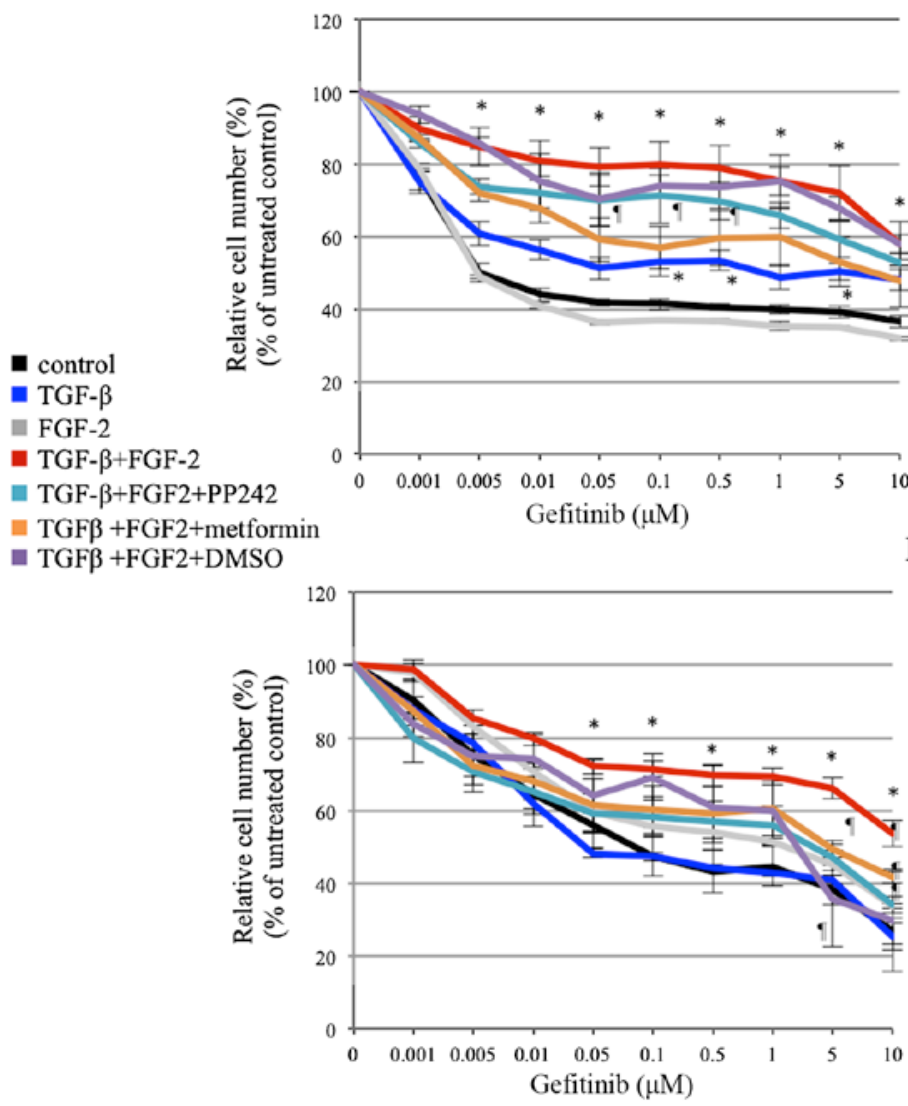

B

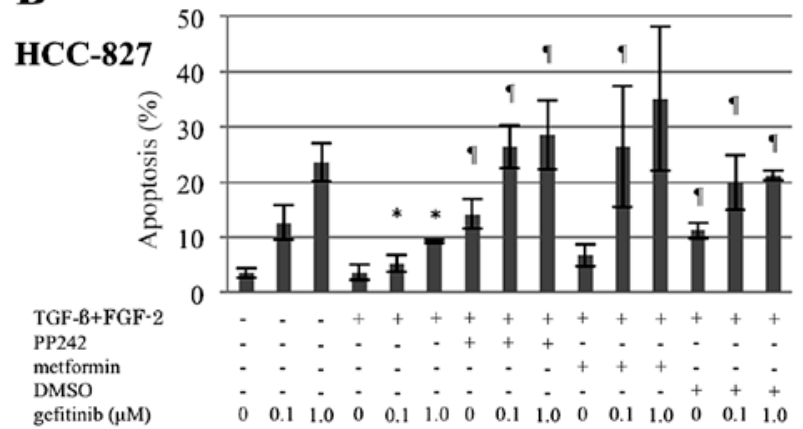

PC-9

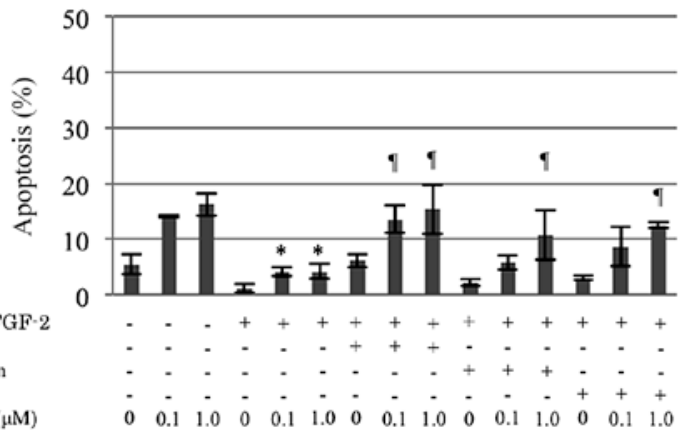

HCC-827

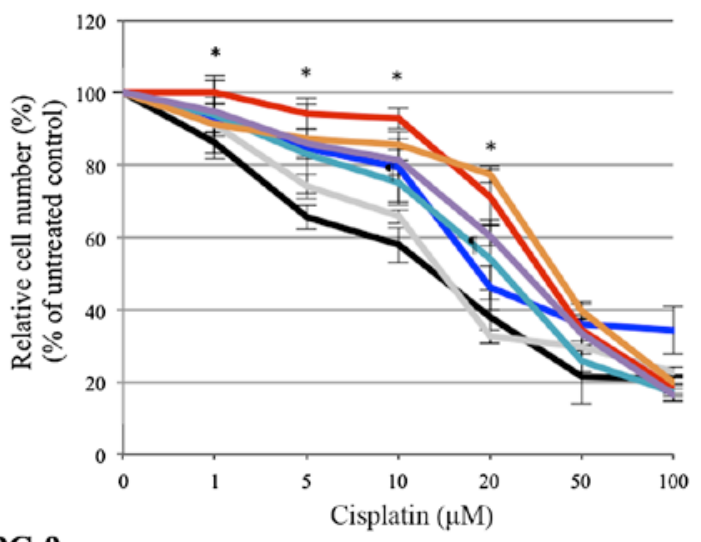

PC-9
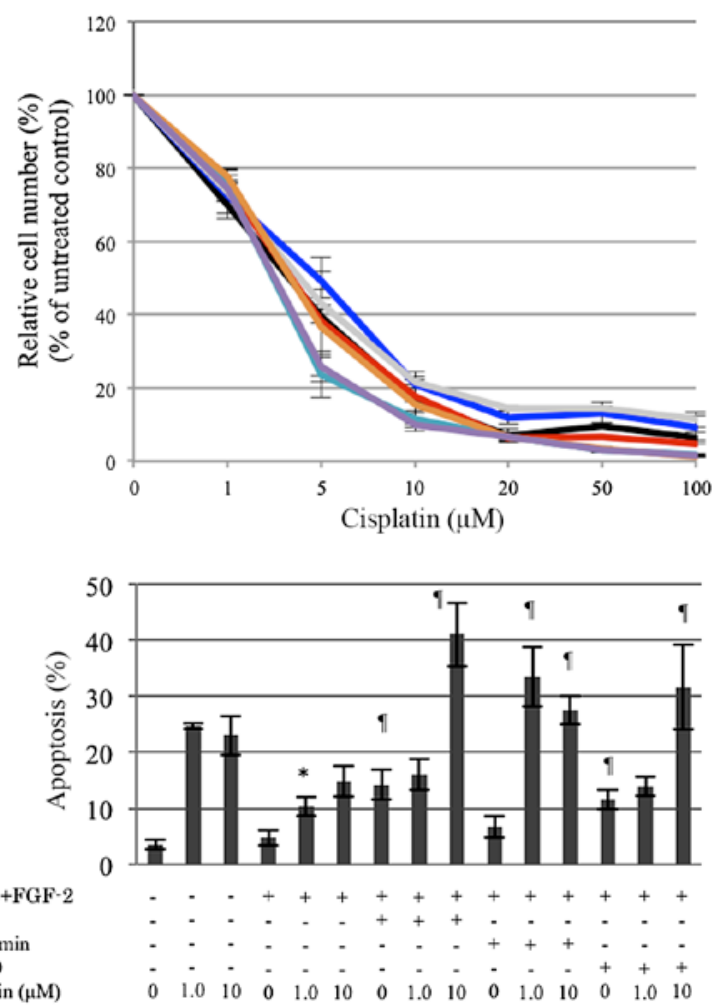

Figure 4. Alterations of sensitivity to gefitinib and cisplatin according to EMT induction and reversion. (A) MTT assay after $72 \mathrm{~h}$ of treatment with gefitinib or cisplatin showed that sensitivity to gefitinib was not significantly altered when the cells were treated with TGF- $\beta$ or FGF- 2 alone, whereas the combination of these 2 agents induced significant resistance to gefitinib. PP242 and metformin partly restored the sensitivity to gefitinib in both cell lines. As to the sensitivity to cisplatin, similar effects were only observed in the HCC-827 cells. The dots and bars represent the means and SEs ( $\mathrm{n}=6$, in triplicate), respectively. (B) Apoptotic cells were counted using Annexin V staining at $24 \mathrm{~h}$ after exposure to gefitinib or cisplatin, then assessed using FACS. The percentages for all the early apoptotic cells and for the necrotic/late apoptotic cells were then calculated. Apoptosis increased with gefitinib or cisplatin treatment in a dosedependent manner in the control (no TGF- $\beta$ /FGF-2). In both cell lines with TGF- $\beta /$ FGF-2-induced EMT, however, apoptosis was significantly suppressed after treatment with gefitinib. Treatment with PP242, metformin, and DMSO significantly restored the sensitivity to gefitinib, as assessed by evaluating apoptosis. Similar effects were also observed for the sensitivity to cisplatin in HCC-827 cells, but not in PC-9 cells. The columns and bars represent the means and SEs $(\mathrm{n}=3$, in triplicate), respectively. Statistically significant differences $(\mathrm{P}<0.05)$ compared with the control (no TGF- $\beta /$ FGF- 2$)$ and TGF- $\beta /$ FGF-2-treated cells are indicated by * and ", respectively, in (A) and (B). 


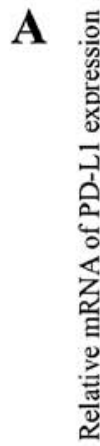

HCC-827

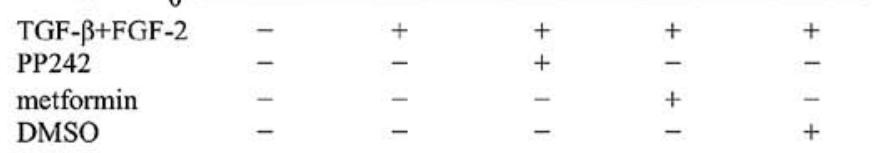

B
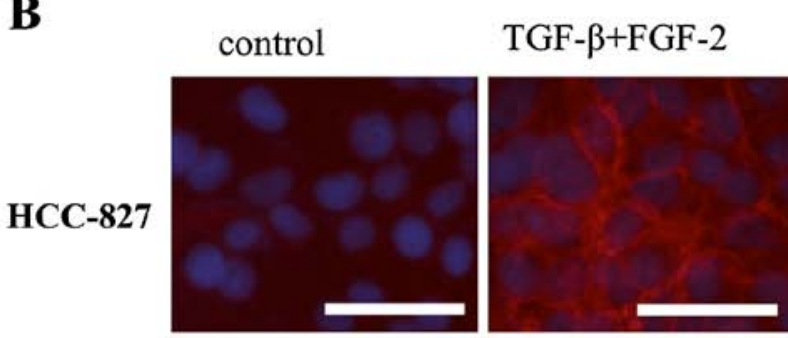

TGF- $\beta+F G F-2$ $+\mathrm{PP} 242$
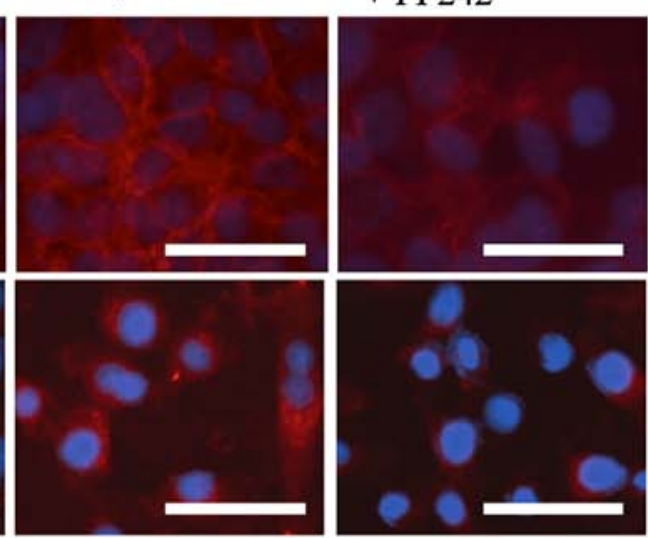

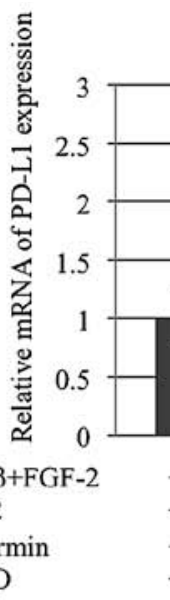

PC-9
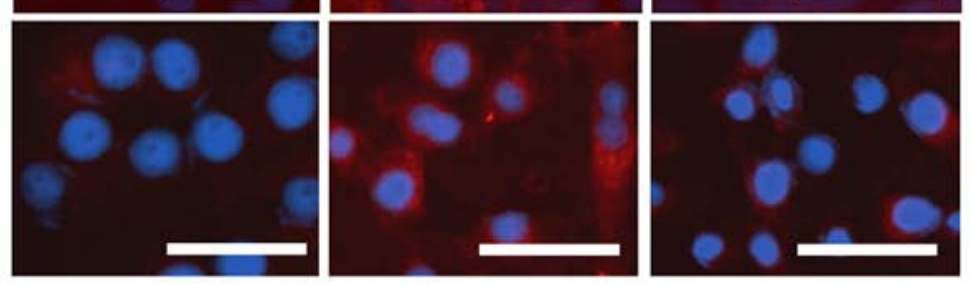

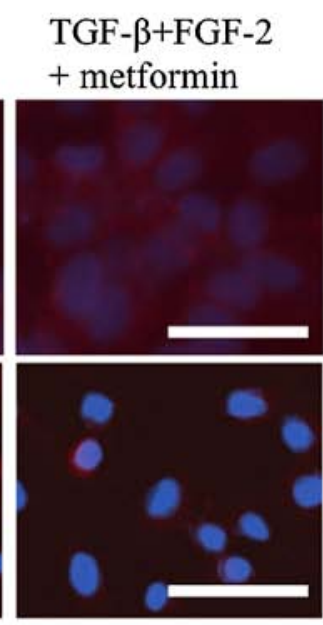

PC-9

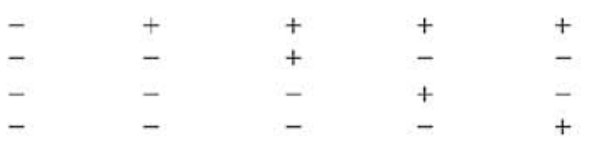

Figure 5. Alterations in PD-L1 expression according to EMT induction and reversion. (A) Relative mRNA expression of PD-L1 normalized to that in control. In the HCC-827 cells, PD-L1 was upregulated in cells treated with TGF- $\beta /$ FGF-2, and metformin and DMSO, but not PP242, suppressed the upregulation. The PC-9 cells showed a tendency toward the same results as those observed for HCC-827 cells. The columns and bars represent the means and SEs ( $\mathrm{n}=3$, in triplicate) of the relative ratio compared with the control, respectively. Statistically significant differences $(\mathrm{P}<0.05)$ compared with the control (no TGF- $\beta /$ FGF-2) and the TGF- $\beta /$ FGF-2-treated cells are indicated by " and ", respectively. (B) Fluorescent immunohistochemistry demonstrating PD-L1 expression on the cell surface supported the findings shown in (A), except that PP242 significantly suppressed EMT-induced PD-L1 overexpression, in contrast to the absence of any effect when assessed using RT-PCR.

suggests the possible involvement of other pathways in EMT, although no evidence to support this hypothesis is presently available. In addition, as also supported by the apoptosis analyses, the induction and reversion of EMT were correlated with drug resistance to an EGFR-TKI and the ability to overcome resistance to an EGFR-TKI, respectively, in both cell lines, and an altered sensitivity to cisplatin was observed solely in HCC-827 cells, again with some differences in the effects of the three reverting agents. Interestingly, the combination of TGF- $\beta$ and FGF-2 had significant effects on drug resistance in this study, whereas TGF- $\beta$ or FGF- 2 alone showed absent or equivocal effects, suggesting a synergistic effect of these cytokines.

The changes in drug sensitivity according to the acquisition and reversion of the EMT phenotype were consistent with those of previous reports, that is, a decreased sensitivity to gefitinib was observed in EGFR mutant NSCLC cells exhibiting an EMT phenotype induced by TGF (27), HGF (28), and IL-6 (29). A decreased sensitivity to cisplatin in NSCLC cells (30) and to trastuzumab in breast cancer cells (31) as a result of EMT induction with TGF, and to etoposide in small cell lung cancer cells with an HGF-induced EMT phenotype (32) were also reported. Previous studies have disclosed that an Erk inhibitor (27) and mTOR inhibitors (26,33-35) restored drug sensitivity affected by the EMT. In addition, metformin was shown to cause EMT reversion through the inhibition of the mTOR, Erk, and JAK/STAT3 pathways $(29,31)$. These findings suggest the involvement of the Erk, mTOR, and JAK/STAT3 pathways in EMT reversion and its relation to drug resistance. Although the mechanisms involved have not yet been defined, other agents such as crizotinib (32), resveratrol (36), tranilast (37), the eukaryotic initiation factor inhibitor GC7 (N1-guanyl1,7-diaminoheptane) (38), propolis (39), eribulin (40) and TTF-1 (41) have been reported to decrease EMT-induced drug resistance. Therefore, this study, in addition to confirming the restoration of drug sensitivity and EMT reversion by an mTOR inhibitor and metformin, provided the new findings that DMSO reverted the EMT and restored drug sensitivity through the inhibition of the mTOR-C1/p70S6K pathway and had some paradoxical effects on other pathways. Although DMSO is known to have multiple effects on cellular functions, such as an increased intracellular calcium concentration 
and the differentiation of embryonal cells and leukemia cells (42-44), its role on modifying the EMT phenotype has not been reported. Furthermore, since DMSO has also been reported to reduce vimentin expression and to promote a fibroblast-like morphology in cultured rat neonatal hepatocytes $(45,46)$, these observations may be reflected by the reversion of the EMT. DMSO also reportedly induces the differentiation of a human promyelocytic leukemia cell line through the activation of the MEK/Erk pathway (47). The activation of the MEK/Erk pathway was also demonstrated in this study, although the activation of the pathway seems to be in the opposite direction for EMT reversion. As the effects of DMSO on EMT reversion appeared to be paradoxical in this study, the biological functions of DMSO should be further clarified.

This study also demonstrated a close relationship between PD-L1 expression and EMT induction/reversion. PD-L1 expression on the surface of cancer cells is known to be important for escaping from host immunity. Although the mechanisms involved in regulating PD-L1 expression are not fully understood, a recent report also disclosed a link between the induction of EMT and the overexpression of PD-L1. This study illustrated a potential mechanism where an EMT activator, zinc-finger E-box-binding homeobox 1, relieved the microRNA-200-induced suppression of PD-L1, leading to $\mathrm{CD}^{+}$tumor-infiltrating lymphocyte-induced immunosuppression (48). Another recent study also demonstrated the overexpression of PD-L1 in the TGF- $\beta$-driven EMT and the downregulation of PD-L1 expression through the inhibition of PI3K or Erk in breast cancer cells (49). TGF- $\beta$ is a well-known immune suppresser related to the Smad3 and non-Smad3 pathways (6). In this study, although EMT induction was related to an elevation in Smad3 expression, its reversion was not related to a decrease in Smad3 expression, whereas PD-L1 expression was elevated in the process of EMT induction and was suppressed during the process of reversion, suggesting the involvements of the non-Smad3 pathways in EMT-driven immune suppression, at least in the PC-9 and HCC-827 cells. The PI3K/Akt and MEK/Erk pathways, which are both common downstream signal pathways of ALK and EGFR, reportedly mediate the modulation of PD-L1 expression in cancer cells with either an $A L K$-translocation or EGFR mutation (50). Taken together, these results suggest that EMT-related immune suppression and its reversion in cancer cells with activated EGFR signaling may occur as a result of changes in PD-L1 expression.

Many fragments of evidence regarding the EMT in cancer cells as it relates to immune-protection, drug sensitivity, and reversion have been provided by many studies. However, this study provided a comprehensive demonstration of the entire story of EMT induction and reversion, including the accompanying changes in drug sensitivity and immune suppression. Moreover, this study identified the mechanisms underlying these observations and suggested that different mechanisms may be involved in different cell lines. We believe that these points are the strengths of this study. The addition of DMSO to the list of EMT-reverting agents together with the disclosure of its unique roles in EMT reversion gives further strength to this study. Nevertheless, this study did have some limitations: i) the study was exclusively performed in two NSCLC cell lines with the same EGFR mutation, ii) the possibility that the observed findings might be limited to cells with activated EGFR cannot be excluded because the change in sensitivity to cisplatin was only modest, iii) the findings are limited to the induction of the EMT through TGF- $\beta$ and FGF-2, and other growth factors and cytokines known to induce the EMT, such as HGF, insulin-like growth factor, and IL-6, were not studied, and iv) all the findings were derived from in vitro experiments lacking interactions between the tumor and cancer microenvironments, which are thought to be very important for some epigenetic changes, including EMT. The last issue seems to be especially crucial in the context of the relationship between the EMT and immune suppression, where interactions between the cancer cells and the host immune cells are critical. Obviously, further elucidation and verification of the observations in other cell lines, both in vitro and in vivo, are needed.

In conclusion, EMT reversion has the potential to overcome drug resistance of cancer cells, especially for treatments involving molecular targeted therapy and immune checkpoint therapy. Further elucidation of the mechanisms underlying EMT reversion and the identification of more potent agents capable of reverting EMT are warranted for clinical applications.

\section{Acknowledgements}

This study was supported by grants from the Ministry of Education, Culture, Sports, Science and Technology in Japan (Kiban-C \#26461182), Chugai Pharmaceutical Co., Ltd., Eli Lilly Japan K.K., Bristol-Myers Squibb Co., Ltd., Japan, Kyowa Hakko Kirin Co., Ltd., Mochida Pharmaceutical Co., Ltd., and Merck Serono Co., Ltd., Japan to Y.T.

\section{References}

1. Prall F: Tumour budding in colorectal carcinoma. Histopathology 50: 151-162, 2007.

2. Thiery JP, Acloque H, Huang RY and Nieto MA: Epithelialmesenchymal transitions in development and disease. Cell 139: 871-890, 2009.

3. Thomson S, Buck E, Petti F, Griffin G, Brown E, Ramnarine N, Iwata KK, Gibson N and Haley JD: Epithelial to mesenchymal transition is a determinant of sensitivity of non-small-cell lung carcinoma cell lines and xenografts to epidermal growth factor receptor inhibition. Cancer Res 65: 9455-9462, 2005.

4. Kurrey NK, Jalgaonkar SP, Joglekar AV, Ghanate AD, Chaskar PD, Doiphode RY and Bapat SA: Snail and slug mediate radioresistance and chemoresistance by antagonizing p53-mediated apoptosis and acquiring a stem-like phenotype in ovarian cancer cells. Stem Cells 27: 2059-2068, 2009.

5. Lee JK, Joo KM, Lee J, Yoon Y and Nam DH: Targeting the epithelial to mesenchymal transition in glioblastoma: The emerging role of MET signaling. Onco Targets Ther 7: 1933-1944, 2014.

6. Kudo-Saito C, Shirako H, Takeuchi T and Kawakami Y: Cancer metastasis is accelerated through immunosuppression during Snail-induced EMT of cancer cells. Cancer Cell 15: 195-206, 2009.

7. Gavert $\mathrm{N}$ and Ben-Ze'ev A: Epithelial-mesenchymal transition and the invasive potential of tumors. Trends Mol Med 14: 199-209, 2008.

8. Grände M, Franzen A, Karlsson JO, Ericson LE, Heldin NE and Nilsson M: Transforming growth factor-beta and epidermal growth factor synergistically stimulate epithelial to mesenchymal transition (EMT) through a MEK-dependent mechanism in primary cultured pig thyrocytes. J Cell Sci 115: 4227-4236, 2002.

9. Derynck R and Zhang YE: Smad-dependent and Smadindependent pathways in TGF-beta family signalling. Nature 425: 577-584, 2003. 
10. Shi Y and Massagué J: Mechanisms of TGF-beta signaling from cell membrane to the nucleus. Cell 113: 685-700, 2003.

11. Chen XF, Zhang HJ, Wang HB, Zhu J, Zhou WY, Zhang $\mathrm{H}$, Zhao MC, Su JM, Gao W, Zhang L, et al: Transforming growth factor- $\beta 1$ induces epithelial-to-mesenchymal transition in human lung cancer cells via PI3K/Akt and MEK/Erk1/2 signaling pathways. Mol Biol Rep 39: 3549-3556, 2012.

12. Shirakihara T, Horiguchi K, Miyazawa K, Ehata S, Shibata T, Morita I, Miyazono K and Saitoh M: TGF- $\beta$ regulates isoform switching of FGF receptors and epithelial-mesenchymal transition. EMBO J 30: 783-795, 2011

13. Shih JY and Yang PC: The EMT regulator slug and lung carcinogenesis. Carcinogenesis 32: 1299-1304, 2011.

14. Chen H, Zhu G, Li Y, Padia RN, Dong Z, Pan ZK, Liu K and Huang S: Extracellular signal-regulated kinase signaling pathway regulates breast cancer cell migration by maintaining slug expression. Cancer Res 69: 9228-9235, 2009.

15. Lau MT and Leung PC: The PI3K/Akt/mTOR signaling pathway mediates insulin-like growth factor 1-induced E-cadherin downregulation and cell proliferation in ovarian cancer cells. Cancer Lett 326: 191-198, 2012.

16. Lyons JG, Patel V, Roue NC, Fok SY, Soon LL, Halliday GM and Gutkind JS: Snail up-regulates proinflammatory mediators and inhibits differentiation in oral keratinocytes. Cancer Res 68 : 4525-4530, 2008.

17. Shintani Y, Okimura A, Sato K, Nakagiri T, Kadota Y, Inoue M Sawabata N, Minami M, Ikeda N, Kawahara K, et al: Epithelial to mesenchymal transition is a determinant of sensitivity to chemoradiotherapy in non-small cell lung cancer. Ann Thorac Surg 92: 1794-1804, 2011

18. Marín-Aguilera M, Codony-Servat J, Reig Ò, Lozano JJ, Fernández PL, Pereira MV, Jiménez N, Donovan M, Puig P, Mengual L, et al: Epithelial-to-mesenchymal transition mediates docetaxel resistance and high risk of relapse in prostate cancer. Mol Cancer Ther 13: 1270-1284, 2014.

19. Kajiyama H, Shibata K, Terauchi M, Yamashita M, Ino K, Nawa A and Kikkawa F: Chemoresistance to paclitaxel induces epithelial-mesenchymal transition and enhances metastatic potential for epithelial ovarian carcinoma cells. Int J Oncol 31: 277-283, 2007.

20. Yang AD, Fan F, Camp ER, van Buren G, Liu W, Somcio R, Gray MJ, Cheng H, Hoff PM and Ellis LM: Chronic oxaliplatin resistance induces epithelial-to-mesenchymal transition in colorectal cancer cell lines. Clin Cancer Res 12: 4147-4153, 2006.

21. Zhuo W, Wang Y, Zhuo X, Zhang Y, Ao X and Chen Z: Knockdown of Snail, a novel zinc finger transcription factor, via RNA interference increases A549 cell sensitivity to cisplatin via JNK/mitochondrial pathway. Lung Cancer 62 : $8-14,2008$.

22. Chang TH, Tsai MF, Su KY, Wu SG, Huang CP, Yu SL, Yu YL, Lan CC, Yang CH, Lin SB, et al: Slug confers resistance to the epidermal growth factor receptor tyrosine kinase inhibitor. Am J Respir Crit Care Med 183: 1071-1079, 2011

23. Sharma SV, Lee DY, Li B, Quinlan MP, Takahashi F, Maheswaran S, McDermott U, Azizian N, Zou L, Fischbach MA, et al: A chromatin-mediated reversible drug-tolerant state in cancer cell subpopulations. Cell 141: 69-80, 2010.

24. Sato M, Shames DS and Hasegawa Y: Emerging evidence of epithelial-to-mesenchymal transition in lung carcinogenesis. Respirology 17: 1048-1059, 2012.

25. Zhang HJ, Wang HY, Zhang HT, Su JM, Zhu J, Wang HB, Zhou WY, Zhang H, Zhao MC, Zhang L, et al: Transforming growth factor- $\beta 1$ promotes lung adenocarcinoma invasion and metastasis by epithelial-to-mesenchymal transition. Mol Cell Biochem 355: 309-314, 2011.

26. Lamouille S, Connolly E, Smyth JW, Akhurst RJ and Derynck R TGF- $\beta$-induced activation of mTOR complex 2 drives epithelialmesenchymal transition and cell invasion. J Cell Sci 125: $1259-1273,2012$.

27. Buonato JM and Lazzara MJ: ERK1/2 blockade prevents epithelial-mesenchymal transition in lung cancer cells and promotes their sensitivity to EGFR inhibition. Cancer Res 74: 309-319, 2014.

28. Ishikawa D, Takeuchi S, Nakagawa T, Sano T, Nakade J, Nanjo S, Yamada T, Ebi H, Zhao L, Yasumoto K, et al: mTOR inhibitors control the growth of EGFR mutant lung cancer even after acquiring resistance by HGF. PLoS One 8: e62104, 2013 .
29. Li L, Han R, Xiao H, Lin C, Wang Y, Liu H, Li K, Chen H, Sun F, Yang Z, et al: Metformin sensitizes EGFR-TKI-resistant human lung cancer cells in vitro and in vivo through inhibition of IL-6 signaling and EMT reversal. Clin Cancer Res 20: 2714-2726, 2014.

30. Yu HG, Wei W, Xia LH, Han WL, Zhao P, Wu SJ, Li WD and Chen W: FBW7 upregulation enhances cisplatin cytotoxicity in non-small cell lung cancer cells. Asian Pac J Cancer Prev 14: 6321-6326, 2013.

31. Cufí S, Vazquez-Martin A, Oliveras-Ferraros C, MartinCastillo B, Joven J and Menendez JA: Metformin against TGF $\beta$-induced epithelial-to-mesenchymal transition (EMT): From cancer stem cells to aging-associated fibrosis. Cell Cycle 9: 4461-4468, 2010

32. Cañadas I, Rojo F, Taus Á, Arpí O, Arumí-Uría M, Pijuan L, Menéndez S, Zazo S, Dómine M, Salido M, et al: Targeting epithelial-to-mesenchymal transition with Met inhibitors reverts chemoresistance in small cell lung cancer. Clin Cancer Res 20: 938-950, 2014.

33. Lamouille $\mathrm{S}$ and Derynck R: Cell size and invasion in TGF-beta-induced epithelial to mesenchymal transition is regulated by activation of the mTOR pathway. J Cell Biol 178: 437-451, 2007.

34. Maru S, Ishigaki Y, Shinohara N, Takata T, Tomosugi N and Nonomura K: Inhibition of mTORC2 but not mTORC1 up-regulates E-cadherin expression and inhibits cell motility by blocking HIF-2 $\alpha$ expression in human renal cell carcinoma. J Urol 189: 1921-1929, 2013

35. Kim EY, Kim A, Kim SK, Kim HJ, Chang J, Ahn CM and Chang YS: Inhibition of mTORC1 induces loss of E-cadherin through AKT/GSK-3 $\beta$ signaling-mediated upregulation of E-cadherin repressor complexes in non-small cell lung cancer cells. Respir Res 15: 26, 2014.

36. Shi XP, Miao S, Wu Y, Zhang W, Zhang XF, Ma HZ, Xin HL, Feng J, Wen AD and Li Y: Resveratrol sensitizes tamoxifen in antiestrogen-resistant breast cancer cells with epithelialmesenchymal transition features. Int J Mol Sci 14: 15655-15668, 2013.

37. Darakhshan S and Ghanbari A: Tranilast enhances the antitumor effects of tamoxifen on human breast cancer cells in vitro. J Biomed Sci 20: 76, 2013.

38. Xu G, Yu H, Shi X, Sun L, Zhou Q, Zheng D, Shi H, Li N, Zhang $X$ and Shao G: Cisplatin sensitivity is enhanced in non-small cell lung cancer cells by regulating epithelial-mesenchymal transition through inhibition of eukaryotic translation initiation factor 5A2. BMC Pulm Med 14: 174, 2014.

39. Kao HF, Chang-Chien PW, Chang WT, Yeh TM and Wang JY: Propolis inhibits TGF- $\beta 1$-induced epithelial-mesenchymal transition in human alveolar epithelial cells via PPAR $\gamma$ activation. Int Immunopharmacol 15: 565-574, 2013.

40. Yoshida T, Ozawa Y, Kimura T, Sato Y, Kuznetsov G, Xu S, Uesugi M, Agoulnik S, Taylor N, Funahashi Y, et al: Eribulin mesilate suppresses experimental metastasis of breast cancer cells by reversing phenotype from epithelial-mesenchymal transition (EMT) to mesenchymal-epithelial transition (MET) states. Br J Cancer 110: 1497-1505, 2014

41. Saito RA, Watabe T, Horiguchi K, Kohyama T, Saitoh M, Nagase T and Miyazono K: Thyroid transcription factor-1 inhibits transforming growth factor-beta-mediated epithelial-tomesenchymal transition in lung adenocarcinoma cells. Cancer Res 69: 2783-2791, 2009.

42. Choi T: Dimethyl sulfoxide inhibits spontaneous oocyte fragmentation and delays inactivation of maturation promoting factor (MPF) during the prolonged culture of ovulated murine oocytes in vitro. Cytotechnology 63: 279-284, 2011.

43. Santos NC, Figueira-Coelho J, Martins-Silva J and Saldanha C: Multidisciplinary utilization of dimethyl sulfoxide: Pharmacological, cellular, and molecular aspects. Biochem Pharmacol 65: 1035-1041, 2003.

44. Szmant HH: Physical properties of dimethyl sulfoxide and its function in biological systems. Ann NY Acad Sci 243: 20-23, 1975.

45. Pagan R, Sánchez A, Martin I, Llobera M, Fabregat I and Vilaró S: Effects of growth and differentiation factors on the epithelial-mesenchymal transition in cultured neonatal rat hepatocytes. J Hepatol 31: 895-904, 1999.

46. Pagan R, Martín I, Llobera M and Vilaró S: Epithelialmesenchymal transition of cultured rat neonatal hepatocytes is differentially regulated in response to epidermal growth factor and dimethyl sulfoxide. Hepatology 25: 598-606, 1997. 
47. Yu HN, Lee YR, Noh EM, Lee KS, Song EK, Han MK, Lee YC, Yim CY, Park J, Kim BS, et al: Tumor necrosis factor-alpha enhances DMSO-induced differentiation of HL-60 cells through the activation of ERK/MAPK pathway. Int J Hematol 87: 189-194, 2008.

48. Chen L, Gibbons DL, Goswami S, Cortez MA, Ahn YH, Byers LA, Zhang X, Yi X, Dwyer D, Lin W, et al: Metastasis is regulated via microRNA-200/ZEB1 axis control of tumour cell PD-L1 expression and intratumoral immunosuppression. Nat Commun 5: 5241, 2014.
49. Alsuliman A, Colak D, Al-Harazi O, Fitwi H, Tulbah A, Al-Tweigeri T, Al-Alwan $M$ and Ghebeh $\mathrm{H}$ : Bidirectional crosstalk between PD-L1 expression and epithelial to mesenchymal transition: Significance in claudin-low breast cancer cells. Mol Cancer 14: 149, 2015.

50. Ota K, Azuma K, Kawahara A, Hattori S, Iwama E, Tanizaki J, Harada T, Matsumoto K, Takayama K, Takamori S, et al: Induction of PD-L1 expression by the EML4-ALK oncoprotein and downstream signaling pathways in non-small cell lung cancer. Clin Cancer Res 21: 4014-4021, 2015 